\title{
Description methods of the properties of composites from oxybiodegradable foil waste and wood
}

\author{
J. Ryszkowska \& K. Sałasińska \\ Warsaw University of Technology, Faculty of Materials Science and \\ Engineering, Poland
}

\begin{abstract}
As part of this work oxydegradable polymer was fabricated and analyzed; it was made from the waste following a 30 day exposure in Xenotest, simulating a 2-year exposure in atmospheric conditions and undergoing a triple injection process. Similar examination was applied to composites containing $32 \mathrm{wt} \%$ of wood fabricated from this polymer. In the course of the examinations two methods of degradation process evaluation of the materials were verified. It was stated that the method utilizing the relationship between peak fields originating from scissoring vibrations of the $\left(-\mathrm{CH}_{2}-\right)$ group with a frequency of ca $1463 \mathrm{~cm}^{-1}$ ensures more accurate results. The results of other examinations of the two groups of materials permit us to state that the manufacturing of composites with wood constitutes an interesting form of the utilization of oxybiodegradable polymers.
\end{abstract}

Keywords: oxydegradable polyethylene, foil waste, recycling, wood.

\section{Introduction}

According to the data by Plastics Europe, European association of plastics manufacturers, some 230 million tons of plastics were produced in 2009 in the world (55 million tons in Europe). About $50 \%$ of the materials constitute polymers intended for the packaging industry, of which $40 \%$ are polyolefines: polyethylene (PE-LD, PE-HD, PE-LLD) and polypropylene (PP).

These polymers are made from petroleum-based synthetic polymers that do not degrade in a landfill or in a compost-like environment. However, increased use of synthetic packaging films has led to serious ecological problems. Several 
approaches to solve the pollution problems caused by polyolefines were developed in the 1970s [1]. One of the solutions was the introduction of prooxidants to the polymers. The pro-oxidants $\mathrm{Co}, \mathrm{Mn}, \mathrm{Cr}, \mathrm{Ni}, \mathrm{Mo}$ and $\mathrm{Fe}$ on $\mathrm{Al} 2 \mathrm{O} 3$ or $\mathrm{SiO} 2$ support [2-6], cause that polymers become susceptible to environmental effect. Polyolefines prepared in this way are called oxo-biodegradable.

Degradation of all polymers follows a sequence in which they are converted into their single oligomeric or monomeric units and later they are utilized as carbon source by the microbes. Lower molecular weight hydrocarbons are more susceptible to attack by microorganisms than the high molecular weight polymer. The degradation of polyolefines with pro-oxidants addition proceeds in a similar way [7-18].

The presence of pro-oxidants, particularly, provided superior functionality and higher degradation rate in PE films. Though their degradation time varies between 18 and several dozen months, they often land up at the rubbish dump after a month of use. Within the framework of the works a selective collection of this type of waste was proposed along with the production of composites with wood, fabricated from them. Such composites can be used in various fields, i.e. as elements for seasonal gardening, auxiliary materials for agriculture, urban greenery, etc. Later on they can serve as valuable energy raw materials.

One of the problems connected with the utilization of products made from such composites is the assessment of their exploitation time.

The assessment of the usefulness of climatically hazard materials is carried out by Xenotest type of equipment [15]. After the exposure in such equipment various properties of polymer materials are examined including, first of all, mechanical properties and thermal analysis. However, since the availability of Xenotests is rather limited, other methods are sought after.

In the current study an attempt has been made to understand the degradation of composites from waste polyolefines with pro-oxidant and wood. The changes in the various physiochemical properties of the polymer were monitored to elucidate the degradation process. As part of work and in order to assess the oxidation process occurring during the degradation of oxydegradable polymers and their composites, methods were verified utilizing spectra obtained with the use of infrared spectroscopy.

\section{Experimental}

\subsection{Materials}

Production waste, degradable polyethylene HDPE, containing $1 \mathrm{wt} . \%$ of prooxidant d2w, from Ecoplastic Poland, (OXY) was a kind of gift from Ecoplastic Poland. Wood fibers - Lignocel C 120 with particle size $70-150 \mu \mathrm{m}$, from J. Rettenmaier \& Söhne GmbH, Germany. 


\subsection{Sampling}

Composite samples were fabricated in two stages. In the first stage, with the use of T-45-25-22T-VS single-screw extruder with screw ratio $\mathrm{L} / \mathrm{D}=29$ and with the head for granulation able to simultaneously extrude six $5 \mathrm{~mm}$ profiles, a granulate was extruded containing $25 \mathrm{wt} . \%$ of wood flour. The extrusion process was conducted at the temperatures of $150 / 160 / 170 / 175 / 175^{\circ} \mathrm{C}$ (starting from the charging hopper). After cooling the extruded rods were ground using a mill for plastics. In the second stage wood flour was added to the granulate obtained from the mixture in such quantity so that its total content in the composite should reach $32 \%$ mass; next, the granulate of composite mixture (or oxybiodegradable polymer) was placed in the bunker of DrBoy $22 \mathrm{~A}$ injection moulding machine. The regranulate and wood fibers as well as the obtained granulates were then dried before each processing stage in DAC6 dryer at $80^{\circ} \mathrm{C}$ for one hour. During the injection of samples the cylinder's temperature, starting from the bunker, amounted to $155,160,170,178$ and $180^{\circ} \mathrm{C}$, injection pressure $800 \cdot 10^{5} \mathrm{~Pa}$, and clamp pressure of $800 \cdot 10^{5} \mathrm{~Pa}$. Injection time was ca $2 \mathrm{~s}$, clamp time $12 \mathrm{~s}$, cooling time $8 \mathrm{~s}$; the total cycle time equaled ca $25 \mathrm{~s}$. From all types of materials samples A1 were fabricated in conformity with the norm EN ISO 527-2 using a 2-cavity mould cooled with water at $40^{\circ} \mathrm{C}$.

In order to verify the influence of injection process on the degradation process of oxydegradable polymers and their composites a 3-time injection process was carried out. Samples obtained in the first injection cycle were ground in an industrial mill, dried and injected. This cycle was performed twice. A description of the achieved materials is presented in Table 1 .

Table 1: Description of the achieved materials.

\begin{tabular}{|l|c|c|c|c|c|c|}
\hline Sample & 1 & 2 & 3 & 1.32 & 2.32 & 3.32 \\
\hline Composites matrix & OXY & OXY & OXY & OXY & OXY & OXY \\
\hline $\begin{array}{l}\text { Amount of wood } \\
\text { [wt.\%] }\end{array}$ & - & - & - & 32 & 32 & 32 \\
\hline Process multiplicity & 1 & 2 & 3 & 1 & 2 & 3 \\
\hline
\end{tabular}

\subsection{Characterization}

Resistance of the materials to accelerated ageing was determined on the basis of analysis of pictures taken with the use of microscopic scanning, Charpy impact tests as well as FTIR analysis of samples after irradiation. The examination was carried out in conformity with PN-EN ISO 4892-1, PN-EN ISO 4892-2 and PNEN ISO 20105-A02:1996.

The samples underwent exposure in Xenotest Alpha High Energy equipped with xenon lamp as radiation source. The examination was carried out for $720 \mathrm{~h}$ with samples being subjected to irradiation of $388,8 \mathrm{MJ} / \mathrm{m}^{2}$ (within the scope of $300-400 \mathrm{~nm}$ ) equivalent to a 2-year exposure in natural conditions [19]. The exposure in Xenotest is shown in Table 2. 
Table 2: $\quad$ Ageing test parameters in Xenotest alpha HE.

\begin{tabular}{|c|c|c|}
\hline Parameter & Phase 1 & Phase 2 \\
\hline Filter & \multicolumn{2}{|c|}{ Xenochrome 300} \\
\hline Luminous intensity E, W/m ${ }^{2}$ & $150 \pm 3$ & $150 \pm 3$ \\
\hline Work mode & $\begin{array}{c}\text { without } \\
\text { revolution }\end{array}$ & without revolution \\
\hline Temperature control & in chamber & in chamber \\
\hline Temperature in chamber ${ }^{\circ} \mathrm{C}$ & $35 \pm 3$ & $30 \pm 3$ \\
\hline Rain & no & yes \\
\hline Relative humidity, $\%$ & $50 \pm 3$ & rain \\
\hline Phase time, min & 102 & 18 \\
\hline
\end{tabular}

SEM picture from the surface of examined samples dusted with gold was achieved using an electronic scanning microscope Hitachi S-2600 with accelerating voltage of $10 \mathrm{kV}$.

Infrared spectra of PURs were collected using a FTIR spectrophotometer (Thermo Electron Corporation model Nicolet 6700). Measurements were carried out using attenuated total reflectance (ATR) technique. Each sample was scanned 64 times at a resolution of $4 \mathrm{~cm}^{-1}$ over the frequency range of 4000-400 $\mathrm{cm}^{-1}$. Analysis of FTIR data enabled to determine the carbonyl index.

Charpy impact resistance using Resil 5,5 hammer by Ceast, wg PN-EN ISO 1792:2001 was defined for samples with notch, size $70 \times 4 \times 10 \mathrm{~mm}$ (cut from samples and formed via injection).

Mechanical properties at static stretching in conformity with PN-EN ISO 5271:1998 and PN-EN ISO 527-2:1998 were examined using the strength machine MTS Q/Test 10. Five 1A samples were analyzed from each type of composite. The samples were stretched at the speed of $10 \mathrm{~mm} / \mathrm{min}$. The measurements were recorded automatically using programme TestXpertII. Determined values: strength in the area of plasticity $(\sigma)$, strain at break $(\varepsilon)$ and Young elasticity modulus (E) of polymers and composites.

Absorption after water soaking was determined basing on the change in the mass of 3 randomly selected samples from a given part of the material. The examination was carried out in conformity with the technology specified in the norm PN-EN 317:1999.

\section{Results and discussion}

In the course of conducted examinations the samples from oxybiodegradable polymer and its composite, fabricated via single injection process, were subjected to exposure in Xenotest. In result of the exposure, simulating a 2-year ageing process in natural conditions a degradation of the examined oxybiodegradable polymers took place (Fig. 1). The degradation was visible in the form of white ovals appearing on a sample not directly subjected to UV radiation (Fig. 1a) as well as in the form of cracking on the surface of a sample 
directly subjected to action of the xenon lamp (Fig. 1b). No such visible changes were observed on the surface of composites (Fig. 2). Degradation of polymers and composites results in the decrease in their impact resistance (Table 3).
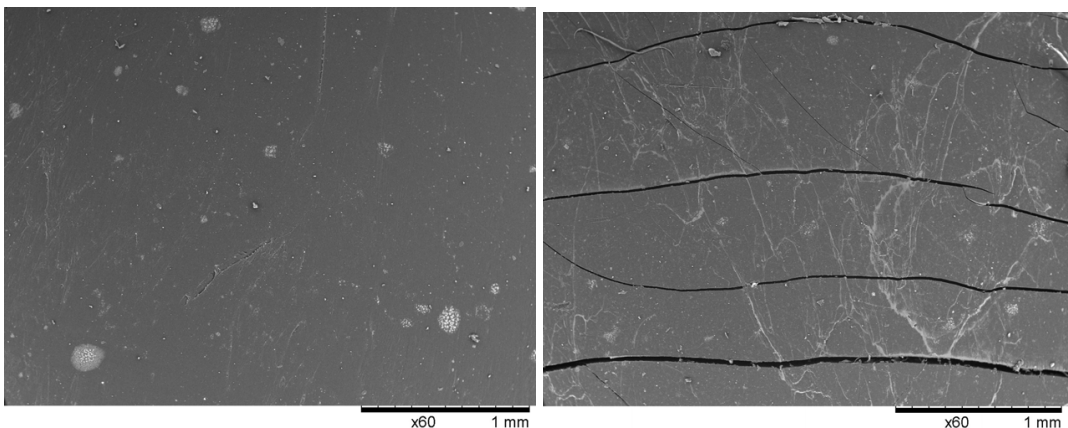

Figure 1: $\quad$ SEM pictures of the surface of oxybiodegradable polymer after 30 days ageing in Xenotest: surface not exposed to a direct radiation of xenon lamp (a), subjected to a direct radiation of xenon lamp (b).
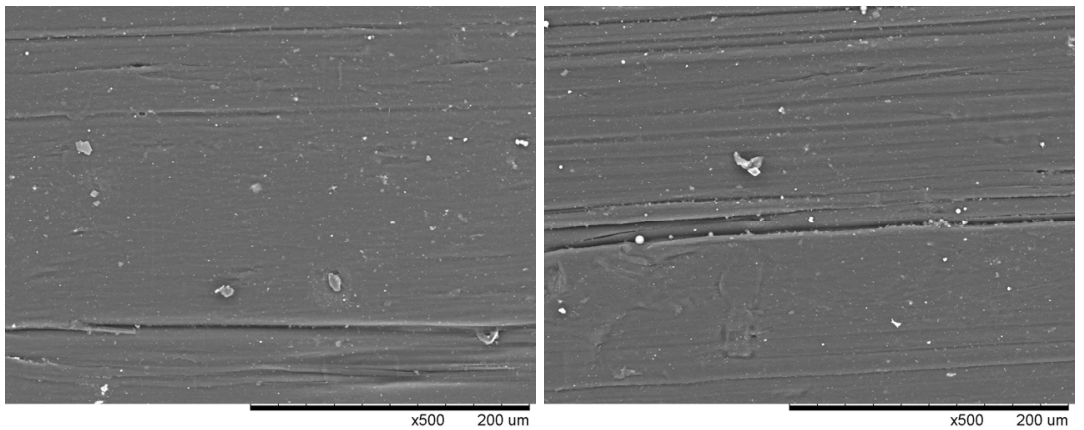

Figure 2: $\quad$ Rys. 2. SEM pictures of the surface of oxybiodegradable polymer with 32 wt.\% of wood, not exposed to a direct radiation of xenon lamp (a), after 30 days ageing in Xenotest (b).

Table 3: The change in impact resistance of oxybiodegradable polymers and composites containing 32 wt.\% of wood, caused by 30 days exposure in Xenotest. 1 - sample of oxybiodegradable polymer, 1.32 - sample of its composite, 1D and 1.32D - samples after exposure in Xenotest.

\begin{tabular}{|l|c|c|c|c|}
\hline Sample & 1 & 1.32 & $1 . \mathrm{D}$ & $1.32 \mathrm{D}$ \\
\hline $\mathrm{U}$, impact resistance, $\mathrm{kJ} / \mathrm{m}^{2}$ & 43.9 & 9.7 & 33.6 & 9.6 \\
\hline
\end{tabular}

In oxybiodegradable polymer the impact resistance after exposure in Xenotest decreased by ca $23 \%$ while that of the composite only by ca $1 \%$. In order to 
assess changes in the structure of polymer and composite, causing the decrease in impact resistance after exposure in Xenotest a spectroscopic analysis (FTIR ATR) of them was carried out. The achieved spectra of polymer and composite are shown in Fig. 3.

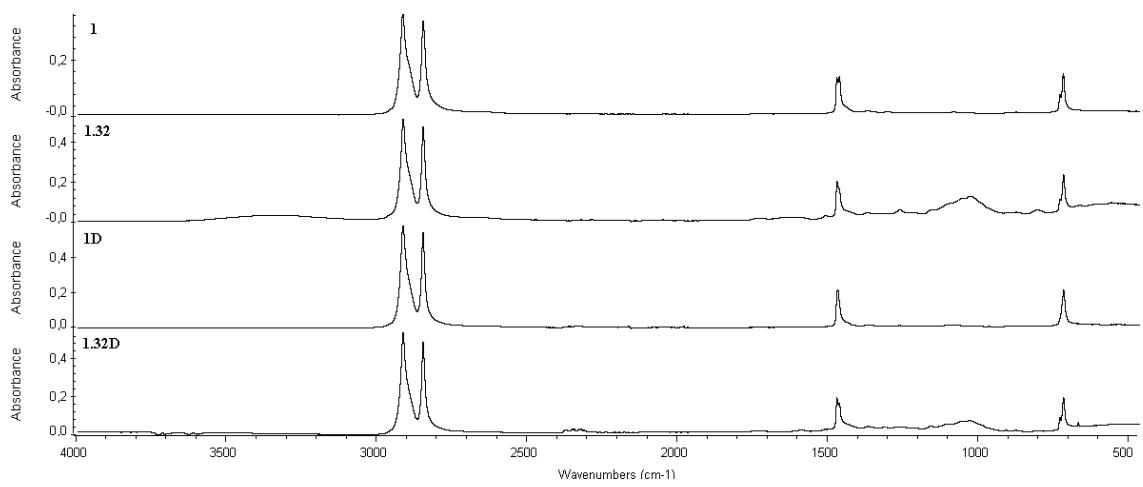

Figure 3: FTIR-ATR spectra of oxybiodegradable polymer samples before (1) and after exposure in Xenotest (1D) and composites before (1.32) and after exposure in Xenotest (1.32D).

Basing on FTIR -ATR spectra carbonyl index (COI) was calculated by two methods. In the first one, proposed by Reddy and co-authors [16] and Corti et al. [14], carbonyl index was determined as the ratio of absorbance of band 1716 $\mathrm{cm}^{-1}$ resulting from the vibrations of $(\mathrm{C}=\mathrm{O})$ carbonyl group and absorbance of band $1468 \mathrm{~cm}^{-1}$ originating from scissoring vibrations of group $\left(-\mathrm{CH}_{2}-\right)$.

$$
C O I=\frac{A_{1716}}{A_{1468}}
$$

In the second method, proposed by Douminge and co-workers [18] and Stark and co-workers [15] carbonyl index was determined as the ratio of absorbance of band $1716 \mathrm{~cm}^{-1}$, resulting from the vibrations of $(\mathrm{C}=\mathrm{O})$ carbonyl group and absorbance of band $2913 \mathrm{~cm}^{-1}$, originating from the asymmetric stretching vibrations of group $\left(-\mathrm{CH}_{2}-\right)$.

$$
C O I=\frac{A_{1716}}{A_{2913}}
$$

The fields of individual bands were determined with the use of OMNIC 7.3 programme. The analysis was carried out after correction of baseline, the spectrum in the analyzed scope was resolved into component bands using the Gaussian curve-fitting. 
Table 4: Calculation results of carbonyl index.

\begin{tabular}{|l|c|c|c|c|}
\hline Sample & 1 & 1.32 & $1 . \mathrm{D}$ & $1.32 \mathrm{D}$ \\
\hline COI calculated acc. to formula (1) & 0.015 & 0.068 & 0.019 & 0.041 \\
\hline COI calculated acc. to formula (2) & 0.005 & 0.019 & 0.006 & 0.012 \\
\hline
\end{tabular}

In the results of the calculation of carbonyl index using the first method it was stated that the index is three times higher than that calculated by the second method according to formula (2) (Table 4). Therefore, it was agreed that the first method will ensure a more accurate analysis of degradation changes in oxybiodegradable polymers and composites with wood, fabricated from them.

To verify this statement an analysis was performed of carbonyl index of the polymer and composite containing $32 \mathrm{wt} . \%$ of wood nanofiller after multiple processing and using the first method (Table 5). Carbonyl index is used to monitor the progress of oxidation process. An increase in COI was observed in oxybiodegradable polymers and composites, which indicates that degradation process in these materials occurs after each processing cycle. After consecutive stages of processing the speed of COI changes in composite with wood decreases, which means that the introduction of wood slows down the degradation process. Also examined were the strength properties, impact resistance and water absorption of the materials; the results are shown in Table 5.

Table 5: Examination results of oxybiodegradable polymer and composites with $32 \mathrm{wt} . \%$ of wood and after multiple injection process.

\begin{tabular}{|l|c|c|c|c|c|c|}
\hline Sample & 1 & 1.32 & 2 & 2.32 & 3 & 3.32 \\
\hline $\begin{array}{l}\text { COI calculated acc. to formula } \\
(1)\end{array}$ & 0.02 & 0.03 & 0.09 & 0.06 & 0.23 & 0.07 \\
\hline U, impact resistance, $\mathrm{kJ} / \mathrm{m}^{2}$ & 38.5 & 8.0 & 36.7 & 9.0 & 31,2 & 11.0 \\
\hline A, humidity content, \% & 0.02 & 3.48 & 0.02 & 3,43 & 0.08 & 3,12 \\
\hline E, elasticity modulus, MPa & 820 & 1740 & 210 & 410 & 205 & 390 \\
\hline $\begin{array}{l}\sigma, \text { stress in the area of plasticity, } \\
\mathrm{MPa}\end{array}$ & 152 & 19 & 105 & 26 & 80 & 27 \\
\hline$\varepsilon$, strain at break, \% & 450 & 4.4 & 280 & 4.9 & 120 & 5.7 \\
\hline
\end{tabular}

The examination results of strength properties confirm that after consecutive processing cycles the degradation process of composites proceeds more slowly than the degradation process of matrix polymers. Also, after consecutive processing cycles water absorbency of the composites favourably decreases.

\section{Conclusion}

Within the framework of the work a possibility of manufacturing practical materials from oxybiodegradable polymers waste was assessed as well as their composites with wood flour filler. The possibility of utilizing recycled oxybiodegradable polymers requires the assessment of their degradation degree 
prior to processing. To this end the use of carbonyl index is proposed. Two methods of its determination were verified. It was stated that the method utilizing the ratio of peak field originating from scissoring vibrations of group.

$\left(-\mathrm{CH}_{2}-\right)$ ensures more accurate results. This method was used for the assessment of degradation degree of oxybiodegradable polymers and their composites subjected to the exposure in Xenotest, simulating a 2-year exposure period in atmospheric conditions and following a three-time injection process. Apart from degradation itself, selected properties of the materials were also evaluated. In result of the examinations it was stated that each processing course accelerates the degradation process of oxybiodegradable polymers. The introduction of wood affects the degradation process of the matrix. Further processing causes smaller changes in the properties of composites than in polymers.

The results show that oxybiodegradable polymer waste, not often utilized so far, may constitute a valuable raw material for manufacturing practical products.

\section{Acknowledgements}

The study has been financed by the National Research and Development Centre within the framework of the project N R15 $002306 / 2009$, titled: Polymer Composites with Biomass

The examinations in Xenotest were carried out by a team headed by Prof. Ph.D. Eng. K. Czaja at the faculty of Chemistry, Opole University, Poland.

\section{References}

[1] Arnaud R, Dabin P, Lemaire J, Al-Malaika S, Chohan S, Coker M, et al. Photooxidation and biodegradation of commercial photodegradable polyethylenes. Polym Degrad Stab 1994; 46:211-24.

[2] Weiland M, Daro D, David C. Biodegradation of thermally oxidized polyethylene. Polym Degrad Stab 1995;48:275-89

[3] Jakubowicz I. Evaluation of degradability of biodegradable polyethylene (PE). Polym Degrad Stab 2003; 80:39-43.

[4] Magagula B. , Nhlapo N., Focke W.W, Mn2Al-LDH- and Co2Al-LDHstearate as photodegradants for LDPE film. Polym Degrad Stab 94 (2009) 947-954.

[5] Roy P.K., Surekha P., Raman R., Rajagopal C., Investigating the role of metal oxidation state on the degradation behaviour of LDPE, Polym Degrad Stab 94 (2009) 1033-1039.

[6] Wiles DM, Scott G. Polyolefins with controlled environmental degradability. Polym Degrad Stab 2006; 91:1581-92.

[7] Chiellini E, Corti A, Swift G. Biodegradation of thermally-oxidized, fragmented low-density polyethylenes. Polym Degrad Stab 2003; 81:34151. 
[8] Hasan F, Shah AA, Hameed A, Ahmed S. Synergistic effect of photo and chemical treatment on the rate of biodegradation of low density polyethylene by Fusarium sp AF4. J Appl Polym Sci 2007; 105:1466-70.

[9] Albertsson A-C, Andersson SO, Karlsson S. The mechanism of biodegradation of polyethylene. Polym Degrad Stab 1987; 18:73-87.

[10] Albertsson A-C, Karlsson S. Three stages in degradation of polymers polyethylene as a model substance. J Appl Polym Sci 1988; 35:1289-302.

[11] Albertsson A-C, Barenstedt C, Karlsson S. Susceptibility of enhanced environmentally degradable polyethylene to thermal and photo-oxidation. Polym Degrad Stab 1992;37(2):163-71.

[12] Sipinen AJ, Rutherford DR. A study of the oxidative degradation of polyolefins. Proc Am Chem Soc 1992;67:185-7.

[13] Hakkarainen M, Albertsson A-C. Environmental degradation of polyethylene. Adv Polym Sci 2004; 169:177-99.

[14] Corti A., Muniyasamy S., Vitali M., Syed H. Imam S.H., Chiellini E. Oxidation and biodegradation of polyethylene films containing pro-oxidant additives: Synergistic effects of sunlight exposure, thermal aging and fungal biodegradation, Polym Degrad Stab 95(2010) 1106-1116.

[15] Stark N.M., Laurent M. Matuana L.M., Surface chemistry changes of weathered HDPE/wood-flour composites studied by XPS and FTIR spectroscopy, Polymer Degradation and Stability 86 (2004) 1-9.

[16] Reddy M.M., Deighton M., Gupta R.K., Bhattacharya S.N., Parthasarathy R., Biodegradation of Oxo-Biodegradable Polyethylene, J Appl. Polym Sci, 111 (2009) 1426-1432.

[17] Jakubowicz I., Narahmadi N., Petersen H., Evaluation of the rate of abiotic degradation of biodegradable polyethylene in various environments, Polym Degrad Stab 91 (2006) 1556-1562.

[18] Douminge L., Mallarino S., Cohendoz S., Feaugas X., Bernard J., Extrinsic fluorescence as a sensitive method for studying photo-degradation of high density polyethylene part I, Current Applied Physics 10 (2010) 1211-1215.

[19] Ryszkowska J., Sałasińska K., Kompozyty z folii oksybiodegradowalnej z recyklingu napelniane drewnem, Polimery 55 (2010) 740-747. 